\title{
Shining a light on food insecurity in Aotearoa New Zealand: Modification of a food security scale for use with individuals who have extreme food security needs
}

a Auckland City Mission, Auckland, New

Zealand; ${ }^{b}$ Faculty of

Education and Social

Work, University of

Auckland, Auckland,

New Zealand
AOTEAROA

NEW ZEALAND SOCIAL WORK 33(4), 14-30.

CORRESPONDENCE TO: Kelsey L. Deane

k.deane@auckland.ac.nz
Helen Robinson ${ }^{\mathrm{a}}$, Kelsey L. Deane ${ }^{\mathrm{b}}$, Allen Bartley ${ }^{\mathrm{b}}$, Mohamed Alansari ${ }^{\mathrm{bi}}$, and Caitlin Neuwelt-Kearns ${ }^{a}$

\begin{abstract}
INTRODUCTION: Food insecurity in Aotearoa New Zealand is a growing concern but quantitative evidence focused on those in most need of support is scarce in the Aotearoa New Zealand context. This limits policy and practice decisions.

METHODS: We modified Parnell and Gray's (2014) Aotearoa New Zealand based food security scale to better capture the severity of food insecurity for individuals living in poverty and used a questionnaire to collect data from a sample of individuals seeking food assistance from foodbanks in Tāmaki Makaurau (Auckland). We used confirmatory factor analysis to assess the psychometric validity of the modified scale. We also tested group differences in food insecurity by gender and ethnicity using analysis of variance and investigated correlations between age, household size and food insecurity.
\end{abstract}

FINDINGS: We found a six-item version of Parnell and Gray's (2014) scale to be psychometrically robust for use with the study population. The sample participants reported concerning and chronic levels of food insecurity. We did not find any group differences.

CONCLUSIONS: At the severe end of the food insecurity continuum, gender and ethnic subgroups appear to suffer at similar levels; however, this does not suggest that different approaches are not required to best meet the needs of different demographic subgroups. Further research is needed to ascertain how similar levels of food insecurity may produce differential effects on wellbeing outcomes for different groups. We recommend more widespread and regular use of the modified scale to assess the experience and impact of food insecurity for individuals living in poverty because it provides a more fine-grained understanding of the severity of food insecurity challenges experienced by individuals seeking food assistance. Fit for purpose measures enable accurate assessments that can better inform policymaking and practice decisions to reduce inequality and promote economic justice.

Keywords: Food insecurity; psychometric validation; gender differences; ethnic differences; poverty 
The sudden economic downturn generated by the Covid-19 pandemic led to a sharp increase in families accessing foodbank services across Aotearoa New Zealand (Salvation Army Social Policy \& Parliamentary Unit, 2020). The subsequent response by the Labour government to provide \$32 million for community food distribution and free school lunches in the 2020 budget provided welcome relief to over-stretched foodbanks across the country. Nevertheless, major policy change and intervention are needed to address the entrenched problem of food insecurity that was present and growing well before Covid-19 hit our shores (Salvation Army Social Policy \& Parliamentary Unit, 2020). Policy decisions are more effective when informed by robust evidence (Gluckman, 2013) but the evidence on food insecurity in Aotearoa New Zealand is limited and restricts possibilities for responsive solutions.

The families and individuals accessing foodbank services in this country are, arguably, those needing the greatest attention from policymakers, but they have largely been lost in the evidence presented in the literature to date. It is common for researchers to experience barriers in effectively engaging with socially and economically disadvantaged groups for research participation (Bonevski et al., 2014). Barriers to engagement may contribute to information gaps, but the problem is exacerbated by the lack of suitable measurement tools. Parnell and Gray (2014) developed a robust measure of food insecurity for use in Aotearoa New Zealand but they designed it to capture prevalence within a national population, not severity at the high end of the food insecurity continuum, where policy and intervention are most urgently needed.

Based on a partnerships project between the Auckland City Mission and University of Auckland researchers, this article describes the psychometric validation of a modified version of Parnell and Gray's (2014) food security scale for use with individuals currently experiencing high levels of food insecurity. The modified measure provides a more fine-grained picture of the severity of food insecurity challenges experienced by individuals seeking food assistance. Using the modified scale, we also report on demographic differences in food insecurity severity for a sample drawn from those seeking assistance from the Auckland City Mission to deepen understanding of this growing problem.

\section{Defining food insecurity}

The term food insecurity was first used in relation to conditions of mass starvation and malnutrition experienced in low-income countries (Reid, 1997). Food insecurity, since then, has been used to describe a similar, albeit broader, experience in higherincome nations that reflects the complex reality of food insecurity that encompasses elements beyond mass starvation and severe malnutrition. Whilst absolute agreement is yet to be reached, commonalities exist. Food insecurity includes the experience of hunger, but it also reflects a context where there is a lack of adequate quality and quantity of food and / or the presence of uncertainty in being able to access what is needed. Food security, in contrast, requires that appropriate food is accessed in socially acceptable ways (Riches, 2018).

\section{Food insecurity in Aotearoa New Zealand}

In the late 1980s, Aotearoa New Zealand's economic and social policies reflected a fundamental shift away from the protective, regulated, state-dominated form of governance of the post-war era, as introduced by the First Labour Government (Easton, 1994), to policies that, in response to the emergence of a globalised world and economy, sought openness, competition and the market's self-regulation. Reducing the role of the state in the provision of social security and regulation of the labour market was key to the changes instituted. 
This is evidenced in the significant cuts made to social security benefits (up to 20\%) in April 1991 (O'Brien, 2014). It is in this context of reduced state support for those on low incomes that the charitable sector stepped in and foodbanks first appeared in Aotearoa New Zealand. Riches (2018) reports that the first foodbank was established at the Auckland City Mission in 1985, quickly developing throughout Aotearoa New Zealand after that and aligning with the international movement of foodbank development, often run by community organisations to accommodate for gaps in state-funded support to address basic human needs.

O'Brien (2014) situates the rise of food insecurity in Aotearoa New Zealand against a "framework of growing inequality and poverty which has shaped so much economic and social policy in this country over the last 25 years" (p. 103) and resulted in the increasing economic injustice that we continue to see today. In Aotearoa New Zealand, rises in the cost of living relative to income have compromised the ability of many to access adequate, decent food, with food often regarded as a discretionary item when household budgets are tight (Graham et al., 2018). Housing costs relative to income have become increasingly unaffordable over the last three decades, particularly for renting households. The proportion of renters spending more than $30 \%$ of income on housing costs (the generally accepted threshold for unaffordable housing) doubled from roughly $20 \%$ of renters in 1988 to over 40\% in 2019 (Statistics New Zealand [StatsNZ], 2020). The Covid-19 pandemic has only accelerated increases in rental costs, with an increase of $11 \%$ to average rents across the country following the lifting of a temporary Covid-related rent freeze in September 2020 (Foneska \& Newton, 2021), at a time when the number of people on benefits was up 23\% from the previous year (Ministry of Social Development [MSD], 2020a). Inflation has had uneven impacts, with increases in the cost of housing, petrol and food, and corresponding decreases in the cost of luxury items such as vacations and electronics. These trends have contributed to higher rates of inflation for beneficiary and low-income households compared to those on higher incomes (StatsNZ, 2021a; Morrison, 2017), putting those on low incomes under increasing financial pressure.

In recent times, food has remained the main reason for needing hardship assistance according to MSD data collected from 2014 to 2019. In the December 2019 quarter, 307,291 grants for food were provided, more than triple the number in December 2014 $(92,167)$ (MSD, n.d.). This has worsened still in the context of Covid-19. In the June 2020 quarter, 566,647 Special Needs Grants for food were approved (MSD, 2020b).

Unfortunately, food insecurity data in Aotearoa New Zealand is limited. The most recent, nationally representative prevalence data on food insecurity in this country is derived from the 2008/9 National Adult Nutrition Survey (University of Otago and Ministry of Health, 2011). The results of that study revealed that, while $59.1 \%$ of households were fully food secure, $33.7 \%$ were moderately food secure, and $7.3 \%$ of households had low food security. Women were generally more likely to be food insecure and Pasifika peoples fared significantly worse (compared to both the general population and all other ethnicities), closely followed by Māori. Since that survey was administered, there has been no further nationally representative data collection on food insecurity for the whole population.

The Ministry of Health (2019) published data from the Aotearoa New Zealand Health Survey for Children for the 2012/13, 2014/15 and 2015/16 years, which offered a glimpse of food insecurity amongst children. Looking at the 2015/ 2016 year, there were just over 917,000 children in Aotearoa New Zealand. The report indicates that just under one in five children experienced severe to moderate food insecurity. Again, both Māori and Pasifika were over-represented. 
Representing only $25.7 \%$ of the child population at the time, $28.6 \%$ of Māori children were identified as food-insecure and $38.8 \%$ of children categorised as foodinsecure were Māori. Pasifika children made up $13.5 \%$ of the child population but $37.1 \%$ were categorised as food-insecure and $26.3 \%$ of food-insecure children were Pasifika (Ministry of Health, 2019). Although these data are nationally representative of children, they do not represent households without children, a significant proportion of our population. Further, the experience of the Auckland City Mission indicates that foodbank usage had increased since 2015 / 2016 but this had occurred well before the surge in demand for food assistance that accompanied the Covid-19 pandemic. In the four years from 2015/16 to 2018/19, food parcel figures increased from 13,714 to 23,020. More recent figures show the pandemic significantly accelerated this increase; in 2019/20, 35,130 food parcels were distributed and in $2020 / 21$, this figure had grown to a staggering 48,679 (Child Poverty Action Group, n. d.).

Beyond prevalence data, there have been a number of geographically based investigations of food insecurity. Since the mid-1990s, Aotearoa New Zealand researchers have attempted to describe the phenomenon of foodbank usage, but this has only occurred for discrete regions, for example Palmerston North (Leslie, 1996), Wellington (Else, 1999), Dunedin (Crack, 2001) and Whangarei (Carne \& Mancini, 2012. McPherson (2006) analysed the sociodemographic characteristics of foodbank clients accessing support through the Christchurch City Mission, the first of its kind in Aotearoa New Zealand. She found that Māori, sole parents and those receiving benefits were significantly over-represented amongst foodbank clients. McNeill (2011) and Graham (2017) both focused on Hamilton and sought to understand the experience of food insecurity in the lives of families and individuals and to illuminate what people do to survive. They, like Garden et al. (2014) in their Auckland City
Mission's Family 100 Report looking into the reality of the lives of 100 families who accessed Mission food services, describe a reality where sourcing food is difficult, time consuming and stressful.

North American research on food insecurity mirrors some of the trends described earlier. Women, particularly those who are sole parents in large, low-income households are over-represented in low food-secure statistics according to large-scale surveys conducted in the Canada and the US, as are indigenous peoples and other marginalised ethnic groups (Coleman-Jensen et al., 2019; Tarasuk et al., 2012). The gendered impact of food insecurity has also been illuminated by qualitative studies. For instance, BuckMcFayden (2015) drew attention to the stories of affected women in Canada who discussed the severe emotional and physical impacts food insecurity had on their lives. The sense of responsibility they bear to care for their family leads to putting themselves last when it comes to nutrition, self-care and accessing necessary medications. Other studies lend support to the sacrifice theory that women sacrifice their own food needs for the wellbeing of their children (Franklin et al., 2012).

Given the finding that Māori and Pasifika groups are also disproportionately affected by food insecurity in Aotearoa New Zealand (McPherson, 2006; University of Otago and Ministry of Health, 2011), culturally specific issues related to food insecurity have been detailed in various research studies completed in Aotearoa New Zealand. For instance, Rush's (2009) and Ahio's (2011) research focusing on Pasifika people highlighted the symbolic role that food plays in their cultures and the related expectations to show hospitality and contribute to their communities through food provision, even if that meant less food for their households. Ahio's (2011) interviews with Tongan health workers and mothers pointed to the central role of mothers and the church in influencing food supply for their families as well as the challenges for food security 
resulting from immigration to Aotearoa where concepts of financial budgeting and property ownership, and access to healthy food are fundamentally different to life in Tonga. To improve circumstances for Tongan families, some recommendations therefore emphasised the need to partner with Tongan churches to design solutions and for community education that was linked to immigration support (Ahio, 2011). Beavis et al.'s (2019) Kaupapa Māori and ethnographic study of four households similarly showed how cultural values associated with manaakitanga, expressed through sharing food with whānau, is linked to a family's mana but also produces stress for families, particularly women. The four Māori households who participated in Beavis et al.'s (2019) study developed strategies to cope with food insecurity that aligned with their cultural values. This included developing food literacy skills, gardening and sharing food; however, the authors highlighted that food security would only be improved with an increase in household income. These studies and others (e.g., Moeke-Pickering et al., 2015) all affirm the need for ethnic-specific understandings of the drivers and experiences of food insecurity to inform culturally responsive solutions.

\section{Measuring food insecurity}

It was the growing demand for food and the rise of foodbanks that inspired Reid (1997) and Parnell (2005) to develop food insecurity measures appropriate for Aotearoa New Zealand. Drawing on international research outlining previously validated measures and focus groups conducted in Aotearoa New Zealand, Reid was the first to develop indicators for use in the New Zealand Ministry of Health's 1997 National Nutrition Survey. Parnell (2005) sought to assess the utility of these questions to adequately measure the existence and degree of food insecurity. Using Rasch analysis, she produced a unidimensional food security scale with good construct validity. Parnell's scale includes eight items that enable differentiation of full, moderate, and low food-secure households in the general Aotearoa New Zealand population. This scale was used in the 2008/9 National Adult Nutrition Survey, the results of which are described earlier. Parnell and Gray (2014) explained the validation process of their food security scale and argued that each of the included eight items are well-grounded in the experiences of food-insecure New Zealanders, having been first informed by exploratory qualitative data, and each item capturing a distinct aspect of the food security construct.

The work of Reid, Parnell and colleagues has established an internally and externally valid food security prevalence measure for Aotearoa New Zealand, but the only nationally representative data available for adults are over 10 years old. There is no comparative data to see if findings are consistent or variable. In the absence of nationally representative data, foodbank usage is often used as a proxy measure of the prevalence of food insecurity in Aotearoa New Zealand (McNeill, 2011). This is, however, only a signpost of the existence of the phenomenon and caution must be applied to these statistics given the lack of shared data amongst foodbank providers and the variable quality of the data ( $\mathrm{O}^{\prime}$ Brien, 2014). Further, all available data does little to reveal trends associated with those at the severe end of the continuum.

\section{Study rationale and aims}

In summary, since the 1980s, there has been a growing concern and attempts to make visible the issue of food insecurity in Aotearoa New Zealand. This is set against a context of radical economic, public and social policy change. Much of the work to assess and understand food insecurity and its consequences in Aotearoa New Zealand has been done in isolated geographical pockets across now a 30-year time span. Despite the piece-meal picture, the difficult, and de-humanising experience of being food insecure in Aotearoa New Zealand has been 
captured and reaffirmed across small-scale or qualitative studies (Garden et al., 2014; Graham, 2017; McNeill, 2011). Different responses have been explored, as described above with reference to Ahio (2011) and Beavis et al.'s (2019) research, and note how different factors influence the experience of food insecurity in Aotearoa New Zealand. Nevertheless, it is unclear if the group differences we see in prevalence at the total population level are mirrored in the lowsecurity end of the spectrum. In addition, we do not have a good grasp of the degree of severity experienced by those seeking food assistance. The sudden increase in people seeking food assistance during the Covid-19 pandemic points to different drivers of food insecurity which may influence different degrees of severity. The need to understand these nuances is particularly pertinent at the present time but this requires fit-for-purpose measures. Robust measures facilitate accurate practice assessments of food insecurity. Accurate assessments then enable analysis of the impact of food insecurity on other important health and wellbeing outcomes and support decisions about how support should be targeted.

Parnell and Gray's (2014) food insecurity scale is a robust tool designed to measure the prevalence of food insecurity in the national adult population, but it is underutilised and does not capture the degree of severity experienced within specific bands (i.e., low, medium and high) of the food insecurity continuum. Accordingly, the objectives of this study were two-fold: 1) to psychometrically validate a modified version of Parnell and Gray's (2014) food insecurity scale that can provide a more nuanced understanding of the severity of food insecurity experienced within an adult sample; and 2) to use the modified tool to describe trends in the severity of food insecurity experienced by individuals seeking food assistance from the Auckland City Mission's foodbank services, including differences by gender, ethnicity, age and household size. Deeper investigation of food insecurity trends is an important step towards developing more responsive policies and interventions for those with the highest food security needs.

Based on trends described in the existing North American and national literature, our hypotheses were:

1) $\mathrm{H}_{1}$ : Women, on average, will report more severe levels of food insecurity;

2) $\mathrm{H}_{2}$ : Māori individuals will report more severe levels of food insecurity, on average, than non-Māori;

3) $\mathrm{H}_{3}$ : Pasifika individuals will report more severe levels of food insecurity, on average, than non-Pasifika individuals;

4) $\mathrm{H}_{4}$ : Household size will be significantly and positively correlated with severity of food insecurity.

5) $\mathrm{H}_{5}$ : Age will not be significantly correlated with food insecurity severity.

\section{Methods}

This study is derived from a questionnairebased research project developed as a collaboration between the Auckland City Mission and a team of University of Auckland researchers. A Statement of Collaboration articulated the interests, rights and responsibilities of each party, including joint ownership of data and strategies to manage any potential conflicts of interest (see Conflict of Interest declaration). The University of Auckland's Institutional Human Participants Ethics Committee granted approval for us to undertake the project.

\section{Questionnaire design}

The results we report for this study are based on analyses of a subset of closed questions from a larger questionnaire that included standardised items and a small number of open-ended questions. Because we intended for data collection to occur at a point where respondents were seeking food support, thus potentially in a vulnerable state, ensuring confidentiality and minimising participant burden were key concerns in 
the design of the questionnaire. To ensure confidentiality, we did not request any individually identifying information. To reduce respondent burden, we included demographic questions on a separate page to the hard-copy questionnaire. This enabled Food Intake Assessors, who were employed by the Auckland City Mission and trained to administer the survey to complete the demographic section (with permission from participating clients) while conducting their food intake assessments. We gave consideration to the use of appropriate questions, easily understood English, a sensible and sequential order of questions and designed the questionnaire to take no longer than 15-20 minutes. We trialled several versions with staff and volunteers of the Auckland City Mission.

\section{Demographic information}

The demographic data for this study included the respondent's age, entered in numeric form in years; gender with response options of Female, Male and Gender Diverse; and ethnicity with response options of NZ European/ Pākehā, NZ Māori, Tokelauan, Fijian, Tongan, Cooks Islands Māori, Samoan, Other Pacific Islands, Chinese, Indian, South-East Asian, Other Asian (e.g., Japanese, Korean), European, and Other (with a request to specify). Respondents could select all options that applied. In addition, respondents were asked to list characteristics (age, nature of relationship and gender) of all the members of their household. This information was used to derive the total number of individuals in the respondent's household.

\section{The food security scale}

The food (in)security scale employed in this study is a modified version of Parnell and Gray's (2014) scale. Their scale measures self-reported food security with eight items and four response options (always, often, sometimes, never). We retained all of Parnell and Gray's (2014) original items; however, to capture greater subtlety in the severity of the food insecurity present within a population already identified as highly food insecure, we asked respondents to consider how often, over the past 12 months, they experienced food insecurity challenges described by the eight items and to select one of eight response options for each, with response options ranging from "every day" at the highest end, to "every couple of weeks" and "once a month" at the mid-points, and "once a year" at the lowest end (higher values represented higher levels of food insecurity). Example items included "How often does food run out in your household due to lack of money?"; "How often is the variety of food you can eat limited by a lack of money", and "How often do you feel stressed because you cannot provide the food you want for social occasions?" (see Ministry of Health, 2019, for full item list). To ascertain the longevity of the challenges faced by respondents, the modified measure also asked how long they had been experiencing the challenges associated with not having enough money for food (response options: Under 1 year, 1-2 years, 2-5 years, 5-10 years, and over 10 years).

\section{Sampling frame and participant recruitment}

The sampling frame for this study included all individuals seeking food assistance over the specified data collection period of JuneDecember 2018 from the Auckland City Mission and its four satellite foodbank sites; all organisational partners consented to be involved in the research. The five sites were all based in the wider Auckland region and included two marae-based services.

Potential participants came to the participating sites seeking support for food. An Intake Assessor, after assuring the individual of this food support, then asked them if they would be willing to participate in the survey. Posters and information sheets placed at each site raised awareness of the study for potential participants before they were invited to participate. We sought only adults over the age of 16 who Food Intake Assessors deemed competent to consent to participate on their 
own at the point of the intake assessment. The University of Auckland Human Participants Ethics Committee deems people aged 16 years or older competent to consent to research participation without approval of a legal guardian.

\section{Questionnaire administration}

As noted earlier, the survey administrators were staff or volunteers who normally acted as the Intake Assessors at their respective foodbanks and all undertook training in questionnaire administration before data collection began. Ethical concerns were discussed and the trainees were directed to prioritise the needs of people presenting over administration of the questionnaires. Intake Assessors are well trained in social service provision and were able to respond to such needs as part of their normal role.

The Intake Assessors reviewed the required ethical documentation with each consenting participant before administering the questionnaire. After an individual agreed to participate, the Intake Assessor sought specific permission to record de-identified demographic data for the participant based on the information given during the assessment. The Intake Assessor attached this information to their questionnaire prior to placement in a sealed envelope. All respondents were given the option of self-administering the questionnaire or having it administered orally and face to face by the Intake Assessor. Intake Assessors administered the questionnaire in hard copy, placed it in a sealed envelope ensuring it contained no identifying information. A team from the Auckland City Mission collected these envelopes on a regular basis from the five different sites.

\section{Analyses and results}

\section{Missing data analysis and imputation}

The Auckland City Mission data collection team entered responses from 728 hardcopy questionnaires collected from the five participating sites into an IBM SPSS $25^{\mathrm{TM}}$ data file. Missing data analysis conducted in SPSS revealed that any additional values missing from the Food Insecurity scale could be considered missing at random as Little's MCAR test was not significant $(\chi 2=45.833, \mathrm{DF}=130, p>.05)$. We therefore decided to impute the missing values using the Expectation Maximisation algorithm

Figure 1. Percentage of Respondents by Ethnicity (Single Combination Coding)

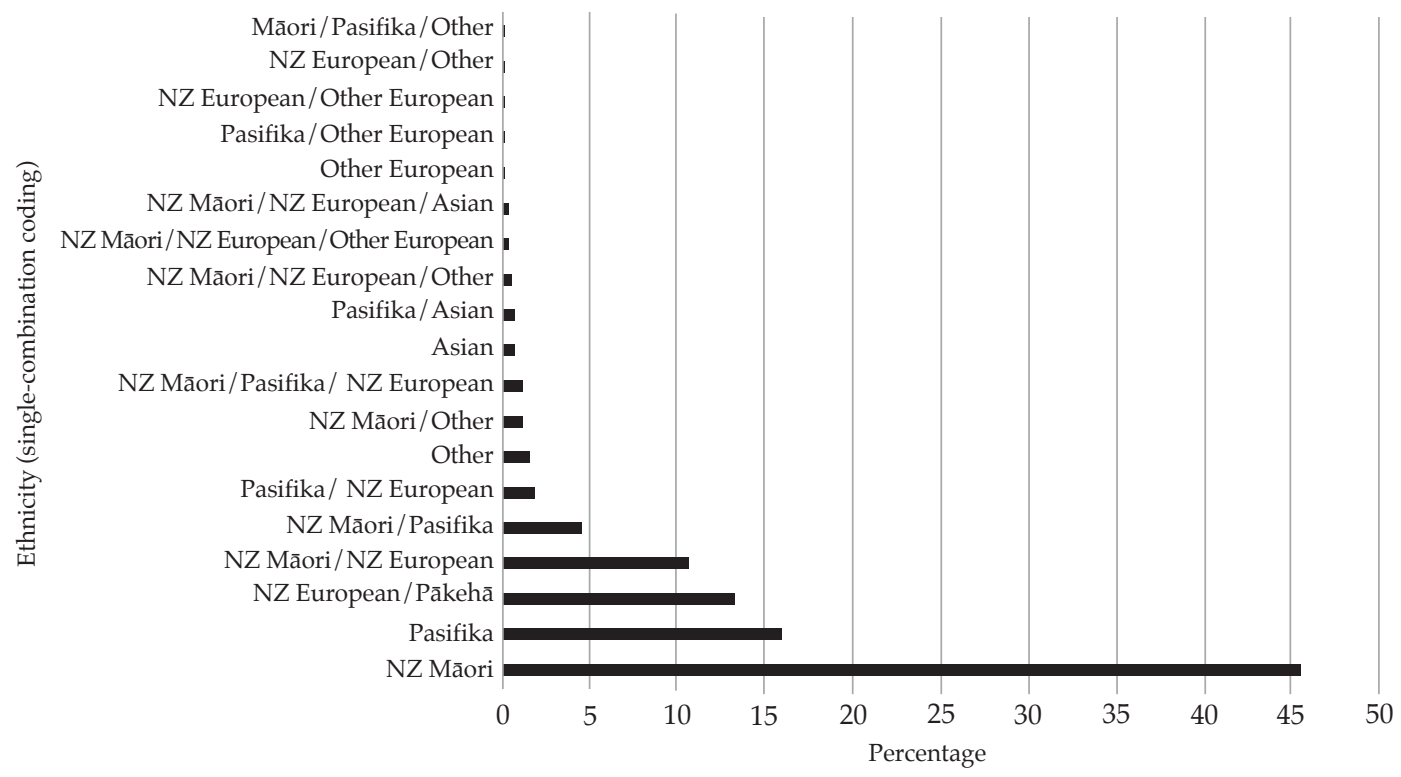




\section{QUANTITATIVE RESEARCH}

in SPSS and this enabled the full sample (of $n=728$ ) to be included in subsequent analyses.

\section{Sample characteristics and representativeness}

With regard to ethnicity, we asked participants to identify with as many

Table 1. Percentage of Respondents by Gender, Ethnicity, Age and Household Size June-December 2018

\section{$\%$ of Respondents}

\section{Gender}

\begin{tabular}{|c|c|}
\hline Male & 30.20 \\
\hline Female & 68.70 \\
\hline Gender Diverse & .50 \\
\hline \multicolumn{2}{|c|}{ Ethnicity (Priority coding) } \\
\hline Māori & 64.00 \\
\hline Pasifika & 18.50 \\
\hline NZ Euro/Pākehā & 13.50 \\
\hline Asian & .80 \\
\hline Other & 1.50 \\
\hline \multicolumn{2}{|l|}{ Age Groups } \\
\hline $17-25$ years & 12.40 \\
\hline 26-35 years & 36.60 \\
\hline $36-45$ years & 30.00 \\
\hline $46-55$ years & 12.50 \\
\hline $56+$ years & 8.40 \\
\hline \multicolumn{2}{|l|}{ Household Size } \\
\hline 1 person & 30.9 \\
\hline 2 people & 13.2 \\
\hline 3 people & 15.7 \\
\hline 4 people & 12.8 \\
\hline 5 people & 12 \\
\hline $6+$ people & 14.6 \\
\hline Total Respondents & 728 \\
\hline
\end{tabular}

ethnic categories as they self-determined. These data were re-coded according to Statistics New Zealand's (2005) Level 1 classification and single/combination ethnicity data are presented in Figure 1. To increase the statistical power of the inferential analysis of ethnic group differences we further categorised ethnicity using the Level 1 categories with priority given to Māori, then Pasifika, Asian, and Other where more than one ethnicity was indicated, as recommended for priority coding by Statistics New Zealand (2005). These proportions are reported in Table 1 and illustrate that more than half of the respondents identified as Māori. Pasifika were the second most prevalent group of respondents.

Table 1 also presents sample proportions by gender, age groups, and household size. Respondents identifying with a female gender were more than double the number of people identifying with another gender. Young adults aged 24-35 were the largest age group represented in the sample followed by adults aged 36-45. Those aged 56 years or older were the smallest age group. Household numbers include both adults and children. Single-person households were the most prevalent, with $30.9 \%$ of people being in this category. However, two-, three-, four- and five-people households represented, cumulatively, the majority of the food-insecure population participating in this research.

The modified eight-item food insecurity scale theoretically represents a unidimensional construct; thus we expected all items to load on a single latent factor. This essentially means that the way individuals respond to the items in the scale was expected to co-vary in a manner that confirms they are all valid, measurable indicators that reflect the same abstract phenomenon of "food insecurity". However, two items had low factor loadings and contributed to poor model fit. These were "How often do you make use of special food grants or foodbanks when you 
do not have enough money for food?" and "How often do you feel stressed because you cannot provide the food you want for social occasions?" The problematic nature of these items was understandable given the sampling frame exclusively focused on people who were at a point of crisis and accessing a foodbank at the time of research participation. We return to this point in the Discussion section.

We therefore removed these items and reassessed the loadings and fit. The remaining six items all had strong unique loadings (standardised regression weights $>$ .70 , see Figure 2 ) and together demonstrated good model fit for a unidimensional food insecurity construct (see Table 2). Although, the model $\chi 2$ is significant and the $\chi 2$ / df value is higher than the recommended criterion for this fit index, this is expected due to this test's sensitivity to sample size and all of the other indices meet the model fit criteria outlined in the Table 2 note. Internal consistency for the six items was also high (Cronbach's $\alpha=.91$ ).

\section{Food insecurity severity trends}

We calculated the means and standard deviations for the food insecurity severity and longevity measures. These are reported in Table 3 for different demographic groups. Overall, the average level of food insecurity severity experienced by the respondents was $5.65(\mathrm{SD}=1.24)$ for the imputed sample which means the great majority of respondents indicated that they were insecure about access to food between once a month (four on the scale) and three or more times a week (seven on the scale). With regard to the length of time this sample of respondents had been dealing with such challenges, $16.89 \%$ of the respondents have not had enough money for food for five years or more. Another 19\% had experienced food insecurity for two to five years. Note that $12.5 \%$ of responses were missing or invalid.

Because the number of gender diverse individuals in the sample was so small $(n=3)$, we created a binomial category of

Figure 2. Confirmatory Factor Analysis for Food Insecurity with Statistically Significant Standardised Regression Weights at $p .<.001$

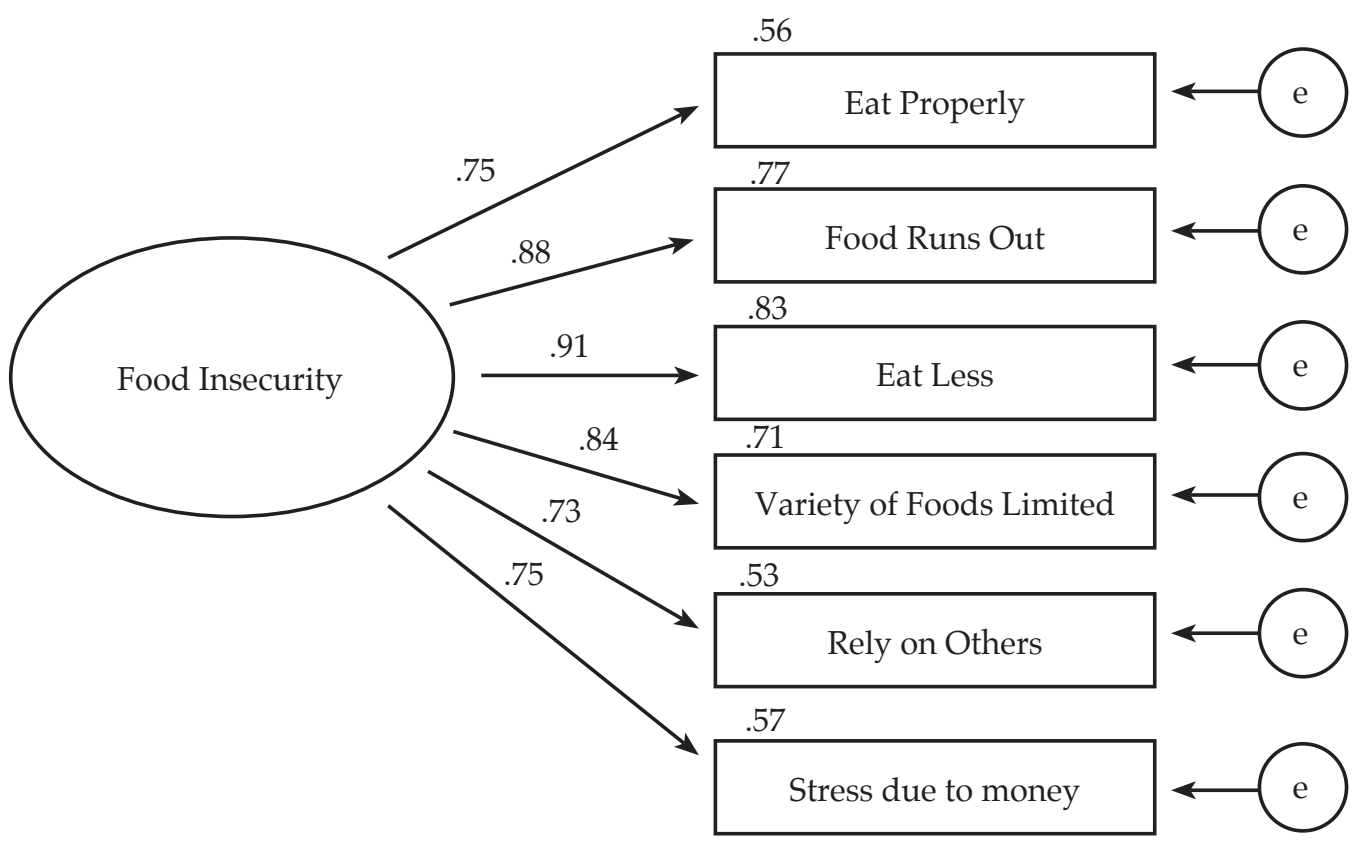


Table 2. Model Fit Indices for Confirmatory Factor Analysis with Fit Criteria

\begin{tabular}{|l|l|l|l|l|l|l|l|l|}
\hline & \multicolumn{7}{|c|}{ Model Fit Indices } \\
\hline Model & $\chi 2$ & df & $\chi 2 / d f$ & RMSEA & SRMR & CFI & TLI & $g^{\wedge}$ \\
\hline 6-item Scale & $49.89^{*}$ & 9 & 5.54 & .079 & .02 & .99 & .98 & .98 \\
\hline
\end{tabular}

Note: $n=728 ; \chi 2$ = Chi-square; * $=p .<.05 ; d f=$ degrees of freedom; $\chi 2 / d f=$ Chi-square to degrees of freedom ratio; RMSEA = root mean square error of approximation; SRMR = standardized root mean square residual; $C F I=$ comparative fit index; TLI = Tucker-Lewis index; $\hat{\gamma}=$ gamma hat.

Criteria for acceptable fit: non-significant $\chi 2 ; \chi 2 / d f<3.0 ;$ RMSEA <.08; SRMR <.05; CFI >.90; TLI >.90; $\hat{\gamma}^{2} .90$ (Alansari, 2017; Fan \& Sivo, 2007).

female and non-female and used a t-test to test gender differences in food insecurity, in accordance with the first hypothesis that females would experience higher levels than non-females. We tested ethnic group differences, as per hypotheses 2 and 3, which stipulated that Māori and Pasifika groups would experience more severe levels than non-Māori and nonPasifika (respectively), using a one-way ANOVA and re-categorised the 5 Level 1 ethnic groups into three. Given the over-

Table 3. Means and Standard Deviations for Food Insecurity Scores by Gender and Ethnicity

\begin{tabular}{|l|r|r|}
\hline & n & \multicolumn{1}{|c|}{$\begin{array}{c}\text { Food Insecurity } \\
\text { Severity } \\
\text { Mean (SD) }\end{array}$} \\
\hline Gender & 220 & $5.64(1.25)$ \\
\hline Male & 500 & $5.65(1.25)$ \\
\hline Female & 3 & $5.58(.24)$ \\
\hline Gender Diverse & 466 & $5.66(1.24)$ \\
\hline Ethnicity & 135 & $5.46(1.34)$ \\
\hline Māori & 98 & $5.80(1.11)$ \\
\hline Pasifika & 6 & $5.71(.67)$ \\
\hline NZ Euro/Pākehā & $98.02(1.24)$ \\
\hline Asian & 11 & $6.05(1.24)$ \\
\hline Other & 728 & $5.65)$ \\
\hline Overall & & \\
\hline
\end{tabular}

representation of Māori and Pasifika groups experiencing food insecurity in previously published, population-based research (University of Otago and Ministry of Health, 2011), we were particularly interested to see if these trends were mirrored in the highly food insecure segment of the population. In addition, the numbers in the Asian $(n=5)$ and Other $(n=11)$ groups were too small to enable meaningful group difference analyses thus we combined these groups with the NZ European / Pākehā group, relabelled as non-Māori / Pasifika. No statistically significant group differences were obtained; therefore, all hypotheses pertaining to group differences by gender and ethnicity were rejected. We calculated Pearson bivariate correlations to test associations between age, household size and food insecurity. Again, none of the bivariate correlations was statistically significant. Accordingly, hypothesis 4, which indicated that age would not be correlated with food insecurity, was supported and hypothesis 5, which suggested household size would be positively correlated with food insecurity, was rejected.

\section{Discussion}

We sought to psychometrically validate a modified version of Parnell and Gray's (2014) Food Insecurity Scale for use with those who have very high food insecurity because the original scale was developed to 
discriminate between three levels (low, mid and high) food security levels within the general adult population in Aotearoa New Zealand. Parnell and Gray's (2014) measure did not enable differentiation of severity within a group of individuals already deemed to have high food insecurity by virtue of their need to seek food assistance from a foodbank. Greater understanding of their food insecurity experiences is needed to inform better policy and intervention initiatives to increase economic justice as these are the individuals with the greatest need for support. As an initial step towards this end, we used the psychometrically validated version of the modified scale to analyse differences in the severity of food insecurity experienced by gender, ethnicity, household size and associations with age. Through a community-university research partnership, we were able to conduct robust analysis on a large sample of people who have been obscured in previous quantitative research on food insecurity in Aotearoa New Zealand. We discuss our insights below.

\section{Modification of Parnell and Gray's food security scale}

First, the confirmatory factor analysis revealed unexpected findings regarding the factor structure of the modified food security scale as applied to our highly food-insecure sample. Although the results supported an anticipated unidimensional food-insecurity construct, two of the eight items did not contribute well to the common variance of the latent food-insecurity construct reflective of the other six items. Theoretically, we could appreciate why this occurred. One problematic item focused on the frequency with which the household required food grant or foodbank assistance. Interestingly, the Ministry of Health (2019) found that this item indicated the most severe level of food insecurity for respondents of the Household Food Insecurity among Children Survey. Because the sampling frame including only those individuals who were seeking food assistance from a foodbank, it is not surprising that the food grant/bank usage indicator operated differently in terms of differentiating levels of severity within the current sample in comparison to when the scale was applied to the general Aotearoa New Zealand population. Similarly, the second problematic item asked about stress associated with not being able to provide food for social occasions. Concerns associated with opportunities to host or contribute food for social occasions are likely rarer for the individuals surveyed for the current study compared to concerns associated with meeting their household's basic needs (i.e., stress associated with not having enough money to eat or enough food, or food of adequate nutritional quality or having to rely on others for food). This highlights the importance of re-assessing the construct validity of previously validated population-based measures when applying them to segments of the population whose experiences are likely to be substantially different from the norm as this improves measurement accuracy.

\section{Group differences in the severity of food insecurity experienced}

We also anticipated closer alignment between the severity of food insecurity experienced by different groups within our sample, based on gender, ethnicity, and household size, and food-insecurity prevalence rates seen in large-scale surveys of broader populations. In North America, women tend to report higher levels of food insecurity, as do people managing larger households (Coleman-Jensen et al., 2019; Tarasuk et al., 2012). Māori and Pasifika groups are over-represented in food insecurity statistics in Aotearoa New Zealand (McPherson, 2006; University of Otago and Ministry of Health, 2011) as are indigenous peoples and marginalised ethnicity groups in the USA and Canada (Coleman-Jensen et al., 2019; Tarasuk et al., 2012). When we consider that foodbank access, on its own, is an important threshold criterion of severe food insecurity (Ministry 
of Health, 2019), the review of gender and ethnic group proportions in the respondent sample also suggests entrenched gender and ethnic disparities.

However, we also found that, once that threshold is met and severity is assessed within the low end of the food-security continuum, these group differences disappear. Importantly, this does not signal that standardised policy and practice responses would meet the needs of foodinsecure individuals and households across these demographic groups. Rather, it only indicates that the severity of the food-insecurity experience is similar and needs to be addressed regardless of one's demographic characteristics. As discussed above, existing research illustrates how people of different demographic groups are differentially impacted by (and find different ways to cope with) food insecurity (Ahio 2011; Buck-McFayden 2015; Franklin et al., 2012; Moeke-Pickering et al., 2015; Rush 2009). For instance, Ahio (2011) recommended partnership with Tongan churches and education programmes focused on budgeting for new Tongan immigrants. Beavis et al. (2019) argued that economic development goals are needed to reduce Māori unemployment and to support upskilling for greater workforce participation and enterprise development, as well as Māori food sovereignty. MoekePickering et al. (2015) also emphasised the need for a national Māori food sovereignty strategy. Research should continue to explore the effectiveness of gender, age and culturally responsive solutions.

The fact that, using a validated measure, we found no group differences in the severity of food insecurity experienced and that, on average, respondents in our sample experienced food insecurity between once a week and every couple of weeks is confronting. This means that multiple times a month, they eat less, run out of food, have a limited variety of food and cannot afford to eat properly, are stressed and have to rely on others for food. Not only that, but almost
$40 \%$ of the respondents in our sample have experienced this reality for more than two years. We show in related research with the same sample that this food insecurity predicts increased psychological distress and reduced emotional wellbeing (Robinson, 2019). Further, when these participants were asked about the main reasons they are food insecure, the great majority $(83 \%)$ indicated it was because their incomes were insufficient to meet their living costs (Neuwelt-Kearns et al., 2021).

In expanding the limited quantitative research focussed on those who are most food insecure in Aotearoa New Zealand, this research seeks to contribute to an evidence base that will inform policymaking and practice. That a substantial proportion of the population-disproportionately female, Māori and Pasifika-must dedicate significant energy to securing adequate food on a weekly to bi-weekly basis is deeply concerning, and a product of the design of current economic and social policy. Disproportionately high inflation experienced by those on low incomes (StatsNZ, 2021a) must be responded to by policy interventions to ensure incomes are adequate-including setting benefits and the minimum wage at liveable rates-as well as interventions to control the cost of living, such as addressing the rising cost of food (StatsNZ, 2021b) and housing (Foneska \& Newton, 2021). It is our hope that the development of more systematic measurement of food insecurity in Aotearoa New Zealand will shed light on the need for a more just economic system that ensures all have access to incomes adequate to experience consistent access to enough, appropriate food.

\section{Study limitations}

The primary focus of this article was to establish the psychometric validity of a modified food insecurity measure so that it could be used more fruitfully with individuals who experience severe challenges with food insecurity. A secondary 
focus was to explore demographic group differences using the modified scale to better understand what the measure could reveal about the food-insecurity experiences with a sample from a single food support organisation. There are limitations that must be carefully considered with respect to the generalisability of the group difference findings.

First, the findings will be biased by the research selection criteria and self-selection bias. Only individuals who Food Intake Assessors deemed competent to provide independent consent to participate were invited to complete the survey. Those who were under the age of 16 and those who presented with mental health or substance use challenges that compromised their ability to provide independent consent are thus not represented in these findings. Intake Assessors were also advised to prioritise the wellbeing needs of participants over research participation thus, in some instances, practice judgement would have influenced decisions about who should be invited to participate. A small proportion $(\sim 15 \%)$ of individuals who seek assistance from the Auckland City Mission do not, or struggle to, speak English and, although the Intake Assessors were available to support participants in answering questions they did not understand on their own, it is likely there is selection bias associated with English language ability.

The findings are also limited in their representativeness because the study scope was restricted to foodbank services operated by the Auckland City Mission within Tāmaki Makaurau. Whilst the Auckland City Mission is one of the largest emergency food distributors in Tāmaki Makaurau, there are other food-assistance providers in the city. The five sites included in the research cover a broad geographical region and diversity of service delivery (e.g., two sites are marae-based) thus our sample captures a reasonably broad sample of individuals seeking emergency food assistance, but we cannot speak to its representativeness for the whole population of food-insecure individuals in Tāmaki Makaurau let alone all of Aotearoa New Zealand.

Finally, the group difference findings are based on crude demographic categorisations (e.g., gender, ethnicity) that do not speak to the reality of how intersectional identities may position people differently in terms of their food-insecurity challenges. Applying an intersectional lens to the analysis would likely reveal important nuances in experiences that are important to consider. Unfortunately, our sample size was limited as to enabling robust analysis at different intersectional subgroup levels.

\section{Future research and policy implications}

As argued above, there is a paucity of quantitative evidence on food insecurity and its impact in Aotearoa New Zealand. The aim of this project was to develop a validated measure of the intensity of food insecurity amongst the least food-secure population in Tāmaki Makaurau, in order to begin to address the lack of robust data about a population that is traditionally difficult for researchers to engage in research. As a result, this research offers a tool that can be used to measure the severity of food insecurity amongst the most vulnerable in Aotearoa New Zealand but the development of the tool is a mere first step. The food security measure used in this survey could be used to further such research by all foodbanks, in a co-ordinated effort to give further voice to this group of people. This would be most effective against a backdrop of bi-annual measurement of the adult and child population, respectively, and with large enough samples to enable analysis of experiences from an intersectional identity lens. Our hope is that these data should be sufficiently compelling to lead to the creation of national food security strategy. Such a strategy would give vision and direction, cohesion and co-ordination to the most 
fundamental of questions: how can Aotearoa New Zealand ensure all its citizens have enough, appropriate food? More effective interventions require better evidence than is currently available. The current study creates a platform for further research.

\section{Conclusion}

The modified version of Parnell and Gray's (2014) food security scale validated in this research allowed us to shine a light on the challenging reality experienced by marginalised individuals who are not well captured in population-based assessments or investigations focused on children and young people. This research also illustrated why measurement beyond foodbank usage is important. Severity trends at the lowest end of the food-security continuum do not mirror population trends with respect to demographic group differences; nevertheless, women, Māori and Pasifika are, consistently, the groups with the most extreme food-security needs in Aotearoa New Zealand.

It is clear that not all citizens in this country have access to enough, nutritionally appropriate food to fuel their health and wellbeing. The surge in demand at foodbanks in the context of Covid-19 has made the need for determined intervention all the more urgent and pressed home the desperate precarity of those on the lowest incomes. For these individuals, the emergency provision of food alone will not address food insecurity. Disruption to the structures that have created, maintained, and exacerbated economic injustice is what is needed, with urgency. Further investment in research on food insecurity is also needed to inform ongoing policy and practice decisions.

Acknowledgements: Administrative support for the project was gratefully received from $\mathrm{K}$. Nalder and $\mathrm{M}$. Hemming and the authors would like to thank the Mission's partners who supported the collection of this data at their sites, Ngā
Whare Waatea Marae, Papakura Marae, St Luke's Parish in Manurewa, and Te Whare Awhina o Tamworth and the Intake Assessors who obtained participant consent and administered the surveys. We also give thanks to the individuals who gave their time to participate in the project.

Declaration of interest: The first author is the current Missioner and Chief Executive Officer at the Auckland City Mission. This study formed one part of her Master of Social and Community Leadership thesis project, which was supervised and supported by the second and third co-authors. The fifth author is also an employee of the Auckland City Mission. A Statement of Collaboration between the University and the Auckland City Mission formalised the partnership and declared the integrity of the research as a shared priority.

Accepted 30 November 2021

Published 23 December 2021

\section{References}

Ahio, L. L. (2011). Vavae Manava: Context and perception of food security for Tongan mothers and health workers [Unpublished master's thesis]. Auckland University of Technology. http://hdl.handle.net/10292/3487

Alansari, M. R. Y. M. (2017). Social-psychological factors and tertiary learning environments: Student perspectives, measures, and influences [Unpublished doctoral thesis]. University of Auckland.

Beavis, B. S., McKerchar, C., Maaka, J., \& Mainvil, L. A. (2019). Exploration of Māori household experiences of food insecurity. Nutrition \& Dietetics, 76, 344-352. https://doi.10.1111/1747-0080.12477

Bonevski, B., Randell, M., Paul, C., Chapman, K., Twyman, L., Bryant, J., Brozek, I., Hughes, C. (2014). Reaching the hard-to-reach: A systematic review of strategies for improving health and medical research with socially disadvantaged groups. BMC Medical Research Methodology, 14, 42. http://www.biomedcentral.com/ $1471-2288 / 14 / 42$

Buck-McFayden, E. V. (2015). Rural food insecurity: When cooking skills, homegrown food, and perseverance aren't enough to feed a family. Canadian Journal of Public Health, 106(3), e140-e146. https://doi.org/10.17269/ CJPH.106.4837

Carne, S., \& Mancini, A. (2012). Empty food baskets: Food poverty in Whangarei. Whangarei Child Poverty Action Group. https://www.cpag.org.nz/news/report-releaseempty-food-baskets-food-poverty/ 
Child Poverty Action Group. (n.d.). Auckland City Mission Food Parcel Demand. https://www.cpag.org.nz/thelatest/current-statistics/food-parcels/

Coleman-Jensen, A., Rabbitt, M. P., Gregory, C. A., \& Singh, A. (2019). Household food security in the United States in 2018. Economic Research Report-270. US Department of Agriculture, Economic Research Service. https://www.ers.usda.gov/publications/pubdetails/?pubid $=94848$

Crack, S. (2001). The face of poverty: Foodbank location and use in Dunedin [Unpublished honours dissertation]. University of Otago.

Easton, B. (1994). Economic and other ideas behind the New Zealand reforms. Oxford Review of Economic Policy, 10(3), 78-94. http://www.eastonbh.ac.nz/ 1994/10/economic_and_other_ideas_behind_the new_zealand_reforms/

Else, A. (1999). Hidden hunger: Food \& low income in Aotearoa New Zealand. New Zealand Network Against Food Poverty.

Fan, X., \& Sivo, S. A. (2007). Sensitivity of fit indices to model misspecification and model types. Multivariate Behavioral Research, 42(3), 509-529. https://doi:10.1080/00273170701382864

Foneska, D., \& Newton, K. (2021, January 27). Rents soar after Covid-19 freeze ends. Stuff. https://www.stuff.co.nz/ life-style/homed/renting/124052014/rents-soar-aftercovid19-freeze-ends

Franklin, B., Jones, A., Love, D., Puckett, S., Macklin, J., \& White-Means, S. (2012). Exploring mediators of food insecurity and obesity: A review of recent literature. Journal of Community Health, 37, 253-264. https://doi.org/10.1007/s10900-011-9420-4

Garden, E., Caldin, A., Robertson, D., Timmins, J., Wilson, T., \& Wood, T. (2014). Speaking for ourselves: The truth about what keeps people in poverty from those who live it. The family 100 research project July 2014. Auckland City Mission.

Gluckman, P. (2013). The role of evidence in policy formation and implementation. A report from the Prime Minister's Chief Science Advisor. Office of the Prime Minister's Science Advisory Committee. http://www.pmcsa.ac.nz/ archives

Graham, R. (2017). The lived experiences of food insecurity within the context of poverty in Hamilton, New Zealand [Unpublished doctoral thesis]. Massey University. http://hdl.handle.net/10179/13001

Graham, R., Stolte, O., Hodgetts, D., \& Chamberlain, K. (2018). Nutritionism and the construction of "poor choices" in families facing food insecurity. Journal of Health Psychology, 23(14), 1863-1871. https://doi.org/10.1177/1359105316669879

Leslie, H. M. (1996). Banking on foodbanks for poverty alleviation?: A critical appraisal of foodbanks' responses to underdevelopment in New Zealand [Unpublished master's thesis]. Massey University. http://hdl.handle. net/10179/5861

McNeill, K. (2011). Talking with their mouths half full: Food insecurity in the Hamilton community [Unpublished doctoral thesis]. University of Waikato. https://hdl.handle.net/10289/5458
McPherson, K. L. (2006). Food insecurity and the food bank industry: A geographical analysis of food bank use in Christchurch [Unpublished master's thesis]. University of Canterbury. http://dx.doi.org/10.26021/6966

Ministry of Health. (2019). Household food insecurity among children in New Zealand. https://www.health.govt.nz/ publication/household-food-insecurity-among-childrennew-zealand-health-survey

Ministry of Social Development. (n.d.). Hardship assistance December 2019 quarter. https://www.msd.govt.nz/aboutmsd-and-our-work/publications-resources/statistics/ benefit/latest-quarterly-results/hardship-assistance.html

Ministry of Social Development. (2020a). Ministry of Social Development benefit fact sheets snapshot - June 2020 quarter. https://www.msd.govt.nz/about-msd-and-ourwork/publications-resources/statistics/benefit/index.html

Ministry of Social Development. (2020b). Ministry of Social Development Benefit Fact Sheets Snapshot September 2020 Quarter. New Zealand Government. https://www.msd.govt.nz/about-msd-and-our-work/ publications-resources/statistics/benefit/index.html

Moeke-Pickering, T., Heitia, M., Heitia, S., Karapu, R., \& Cote-Meek, S. (2015). Understanding Māori food security and food sovereignty issues in Whakatane. MAI Journal (Online), 4(1), 29-42. http://www.journal. mai.ac.nz/content/understanding-m\%C4\%81ori-foodsecurity-and-food-sovereignty-issues-whakat $\% \mathrm{C} 4 \% 81$ ne

Morrison, T. (2017, May 4). Beneficiaries hardest hit by inflation. NZ Herald. https://www.nzherald.co.nz/ business/beneficiaries-hardest-hit-by-inflation/ OUSS5OWG647YP2MJS7CHFLFL24/

Neuwelt-Kearns, C., Nicholls, A., Deane, K. L., Robinson, H., Lowe, D., Pope, R., Goddard, T., van der Schaaf, M., \& Bartley, A. (2021). The realities and aspirations of people experiencing food insecurity in Tāmaki Makaurau. Kotuitui: New Zealand Journal of Social Sciences Online. https://doi.org/10.1080/1177083X.2021.1951779

O'Brien, M. (2014). Privatizing the right to food: Aotearoa New Zealand. In G. Riches \& T. Silvasti (Eds.), First world hunger revisited: Food charity or the right to food? (pp. 102-116). Palgrave MacMillan.

Parnell, W. (2005). Food security in New Zealand [Unpublished PhD thesis]. University of Otago.

Parnell, W. R., \& Gray, A. R. (2014). Development of a food security measurement tool for New Zealand households. British Journal of Nutrition, 112 (8), 1393-1401. https://doi.org/10.1017/S0007114514002104

Reid, J. (1997). Developing food insecurity indicators for New Zealand [Unpublished master's thesis]. University of Otago.

Riches, G. (2018). Food bank Nations: Poverty, corporate charity and the right to food. Routledge.

Robinson, H. (2019). Shining a light on food insecurity in Aotearoa New Zealand [Unpublished PhD thesis]. University of Auckland.

Rush, E. (2009). Food security for Pacific Peoples in New Zealand. A report for the obesity action coalition. Obesity Action Coalition.

Salvation Army Social Policy \& Parliamentary Unit. (2020). COVID-19 social impact dashboard, 22 May 2020. https://www.salvationarmy.org.nz/article/sppu-covid19social-impact-dashboard-report-4 


\section{ORIGINAL ARTICLE}

Statistics New Zealand. (2005). Understanding and working with ethnicity data: A technical paper. DOI:10.13140/ RG.2.1.1347.0804.

Statistics New Zealand (2020). Housing in Aotearoa: 2020. https://www.stats.govt.nz/reports/housing-inaotearoa-2020

Statistics New Zealand (2021a). Annual inflation almost three times higher for beneficiaries, 5 February 2021. https://www.stats.govt.nz/news/annual-inflation-almostthree-times-higher-for-beneficiaries

Statistics New Zealand (2021b). Food prices rise for sixth consecutive month, 13 October 2021. https://www.stats. govt.nz/news/food-prices-rise-for-sixth-consecutivemonth

Tarasuk, V., Mitchell, A., Dachner, N. (2012). Household food insecurity in Canada, 2012. PROOF Food Insecurity and Policy Research. https://proof.utoronto.ca/foodinsecurity/

University of Otago and Ministry of Health. (2011). A focus on nutrition key findings of the 2008/09 New Zealand adult nutrition survey. Ministry of Health. https://www.health. govt.nz/publication/focus-nutrition-key-findings-2008-09nz-adult-nutrition-survey

\section{(Endnotes)}

1 Dr Mohamed Alansari was affiliated with the Faculty of Education and Social Work at the University of Auckland at the time the research was conducted. He has since moved to the New Zealand Council for Educational Research. 